\title{
Light pollution: Assessment of sky glow on two dark sky regions of Portugal
}

\section{Raul Cerveira Lima, José Pinto da Cunha \& Nuno Peixinho}

To cite this article: Raul Cerveira Lima, José Pinto da Cunha \& Nuno Peixinho (2016) Light pollution: Assessment of sky glow on two dark sky regions of Portugal, Journal of Toxicology and Environmental Health, Part A, 79:7, 307-319, DOI: 10.1080/15287394.2016.1153446

To link to this article: https://doi.org/10.1080/15287394.2016.1153446

\section{Published online: 30 Mar 2016.}

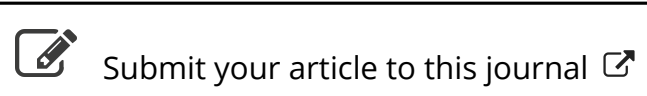

Џlll Article views: 269

View Crossmark data ¿ 


\title{
Light Pollution: Assessment of Sky Glow on two Dark Sky Regions of Portugal
}

\author{
Raul Cerveira Lima (i) ${ }^{\mathrm{a}, \mathrm{b}}$, José Pinto da Cunha (10) ${ }^{c}$ and Nuno Peixinho $\mathbb{1}^{\mathrm{b}, \mathrm{d}}$ \\ aPhysics, School of Allied Health Technologies of the Polytechnic Institute of Porto, Portugal; ${ }^{b} \mathrm{CITEUC}$, Centre for Earth and Space Science \\ Research of the University of Coimbra, Observatório Astronómico da Universidade de Coimbra; 'Physics Department, University of Coimbra; \\ dUnidad de Astronomía, Fac. Cs. Básicas, Universidad de Antofagasta, Chile
}

\begin{abstract}
Artificial light at night (ALAN), producing light pollution (LP), is not a matter restricted to astronomy anymore. Light is part of modern societies and, as a consequence, the natural cycle day-night (bright-dark) has been interrupted in a large segment of the global population. There is increasing evidence that exposure to certain types of light at night and beyond threshold levels may produce hazardous effects to humans and the environment. The concept of "dark skies reserves" is a step forward in order to preserve the night sky and a means of enhancing public awareness of the problem of spread of light pollution worldwide. The aim of this study was to assess the skyglow at two sites in Portugal, the Peneda-Gerês National Park (PNPG) and the region now known as Dark Sky Alqueva Reserve. The latter site was classified as a "Starlight Tourism Destination" by the Starlight Foundation (the first in the world to achieve this classification) following a series of night sky measurements in situ described herein. The measurements at PNPG also contributed to the new set of regulations concerning light pollution at this national park. This study presents the first in situ systematic measurements of night sky brightness, showing that at the two sites the skies are mostly in levels 3 to 4 of the Bortle 9-level scale (with level 1 being the best achievable). The results indicate that the sources of light pollution and skyglow can be attributed predominantly to contamination from nearby urban regions.
\end{abstract}

Light pollution (LP) and sky glow increase as a consequence of expansion of urbanized areas (Walker, 1977) on a scale that depends on the lighting planning of such areas. The creation of "dark sky preserves" is not per se sufficient to maintain the quality of those areas unless other accompanying measures are taken to prevent propagation of LP within and in the vicinity of those areas. The assessment of the places of study regarding sky brightness is then of the utmost importance in order to preserve and improve dark sky quality. Being recognized as a source of pollution with effects beyond astronomy including on human health, a permanent record of the night sky darkness becomes a necessity to trace the evolution of LP. This investigation quantified the sky darkness in two large areas of Portugal, shown in Figure 1, aiming to be a starting point to a permanent record of LP levels at those locations. A similar project is underway in Galicia (north of
Spain), where 13 stations are recording on a permanent basis the brightness of local night sky since September 2013 (Bará, 2014).

\section{Light pollution}

As artificial light at night (ALAN) increases globally accompanying demographic growth, this is associated with enhanced night brightness. Due to this change in the natural environment, various fields of research recently became involved in the assessment of observed or inferred effects of ALAN. As of December 8, 2014, the International Dark-Sky Association (IDA) on its website defined light pollution (LP) as "any adverse effect of artificial light, including sky glow, glare, light trespass, light clutter, decreased visibility at night, and energy waste." Bad public and private lighting, meaning the use of nonshielded streetlights, scenic light projectors directed upward, and advertising panels, together with

CONTACT Raul Cerveira Pinto Sousa Lima raul.s.lima@gmail.com @ Área Técnico-Científica de Física, Escola Superior de Tecnologia da Saúde do Porto/ Instituto Politécnico do Porto, Rua Valente Perfeito, 322, 4400-330 Vila Nova de Gaia, Portugal.

Color versions of one or more of the figures in the article can be found online at www.tandfonline.com/uteh

(C) 2016 Taylor \& Francis 


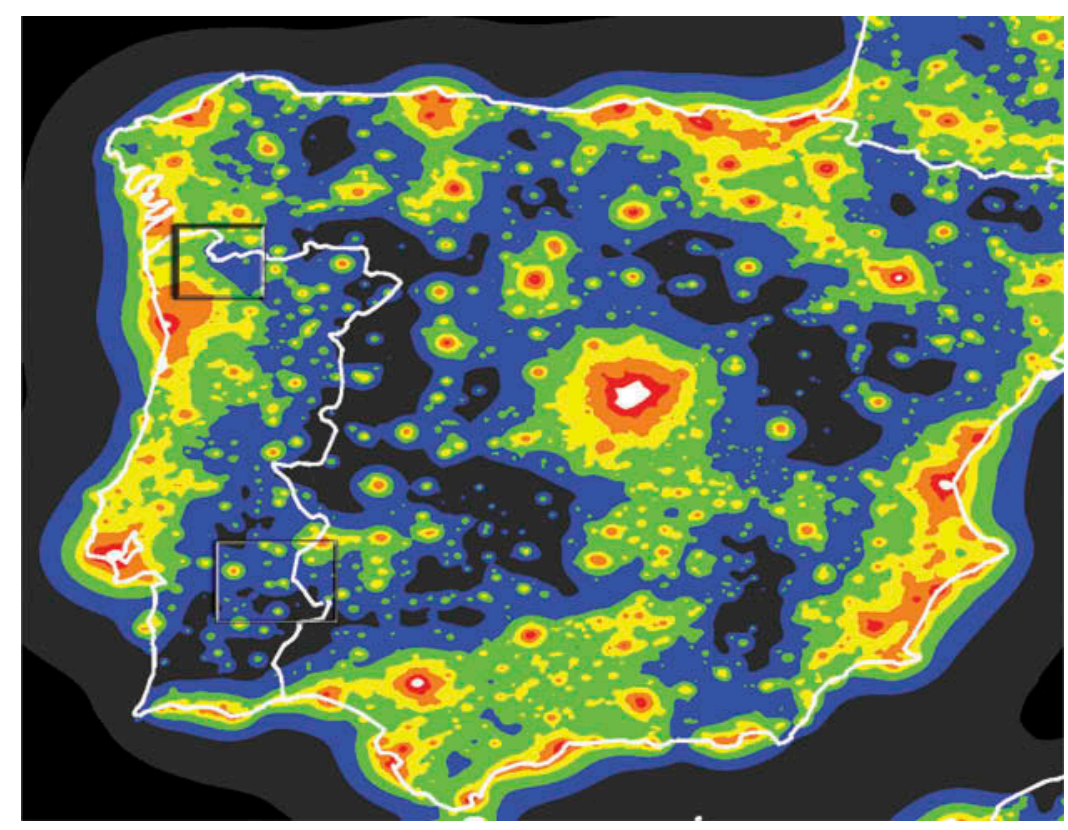

Figure 1. Map of the artificial night sky brightness of the Iberian Peninsula. The areas of study lie inside the two boxes superimposed on the map (PNPG, box at top left; Alqueva, box at bottom left). Darker areas represent darker skies. White areas represent the brightest skies, followed by red and orange. (Adapted from Cinzano et al., 2001).

manifestly excessive artificial light sources, are main causes of outdoor LP and skyglow. Downward light also contributes to skyglow by reflection from buildings and off the ground. However, Luginbuhl et al. (2009) found that even a small fraction of direct upward emission from nonshielded fixtures on dark skies exerts greater impact on skyglow than reflection off the ground. The same study showed that "the skyglow increase from the near horizontal rays is 6 to 160 times as great as that of an equal flux directed downward and reflected off the ground" (Luginbuhl et al., 2009). Since public illumination is necessary and reflection is unavoidable, longknown solutions to minimize skyglow include a reduction of light emission and use of full cut-off fixtures (Waldram, 1972).

\section{The growing range of known effects of light pollution (LP)}

Residents of large cities are almost totally deprived from viewing a starry night. The "Declaration in Defence of the Night Sky and the Right to Starlight" (stated by the conjoint UNESCO, UN World Tourism Organization [WTO], and International Astronomical Union [IAU]) considers that "an unpolluted night sky that allows the enjoyment and contemplation of the firmament should be considered an inalienable right equivalent to all other socio-cultural and environmental rights. Hence the progressive degradation of the night sky must be regarded as a fundamental loss" (Starlight, 2007, p. 456), and that "the intelligent use of artificial lighting that minimizes sky glow and avoids obtrusive visual impact on both humans and wildlife needs to be promoted. This strategy would involve a more efficient use of energy so as to meet the wider commitments made on climate change, and for the protection of the environment" (Starlight, 2007, p. 457).

Although lighting design and road traffic plans generally take LP into account, the primary reason to study LP on the type of human-made skyglow was initially motivated by the needs of both professional and amateur astronomers. However, other undisclosed LP effects started to emerge. A resolution passed by the American Medical Association (AMA) on June 2012 stated that "pervasive use of nighttime lighting $\ldots$ creates potentially harmful health effects and/or hazardous situations with varying degrees of harm" (AMA 2012). Recent investigations in animals and humans showed that "light at night triggers daytime biology, 
disrupting sleep, hormone regulation, and metabolism, and abolishes the darkness essential for regulating our circadian clock" (Stevens et al. 2013). Although there is still debate on the effects of LP on health, some studies demonstrated modifications of circadian rhythm (Stevens, 2006) with implications on obesity (Wyse et al. 2011) and observed malignant growth in tumor models (Filipski et al., 2006). Other recent studies suggested that LP is a risk factor for human breast and prostate cancer (Haim and Portnov, 2013) or colorectal tumors among women working on rotating night shifts (Schernhammer et al., 2003).

Melatonin is a known antioxidant and a freeradical scavenger hormone produced predominantly by the pineal gland that regulates the circadian cycle in humans and animals and is also present in plants (Tan et al., 1993). Reduction in production of melatonin attributed to exposure to artificial light at night is currently under investigation as a possible cause of malignant effects (Jasser et al., 2006; Bullough et al., 2006; Navara and Nelson, 2007; Liang et al. 2011; Proietti et al. 2013). Since the effects of exposure to light at night are dependent on factors such as light intensity, wavelength, concentration, and the sensitivity of the exposed individual, the consequences on human health still remain to be determined. An extensive compilation and analysis of the studies carried to assess the impact of light on health was published by the International Agency for Research on Cancer (IARC) (IARC, 2010). That was the first time the IARC included the evaluation of shift-work as a potential carcinogenic risk factor.

Since wasted light is also wasted energy, indirect effects of LP include a supplementary consumption of natural resources and consequent increase in air pollution, known to be potentially hazardous to health (Costa, 2004; Krzyzanowski, 2008; Costa et al., 2014). It is currently well accepted that air pollution derived from fossil fuels combustion, which is one of the major forms of energy production, "causes a spectrum of health effects from eye irritation to death" (Cohen et al., 2005). Investigations on LP-mediated effects on biodiversity is also emerging, such as on nocturnal fauna (Longcore and Rich, 2006, p. 415) or the disorientation of migratory birds (Gauthreaux and Belser, 2006, p. 86).

Currently, there is still debate on the impacts of artificial light at night on the environment. After millions of years of evolution under natural lightdark cycles, species are facing a new aspect in their environment. The effects of LP on some species might in some cases be positive, as on the prey rate intake rise in gray plovers (Pluvialis squatarola) (Santos et al., 2010). However, predominant observations indicate either deleterious or unanticipated effects occurring (for a comprehensive review of effects of LP on the environment see Gaston et al., 2013).

Light pollution effects are not solely related to the luminous emittance but also depend upon spectral distribution. The same quantity of light emitted by a low-pressure sodium $(\mathrm{Na})$ vapor streetlamp affects the environment differently than an equivalent mercury ( $\mathrm{Hg}$ ) vapor lamp. The former has a narrow spectrum, which is more readily filtered (for astronomical purposes) in comparison to the latter. The spectral bluish component (short-wavelength emission) present in $\mathrm{Hg}$ vapor lamps or light-emitting diodes (LED) sources affects sleep (Falchi et al., 2011) and biodiversity (Stone et al., 2012), and their broader spectra is more difficult to supress. Some data indicate that even at "low ambient light levels (c. 40 lux), light can impact directly upon sleep EEG characteristics" (Chellappa et al., 2013).

Light pollution effects on the skyglow may be considered as instantaneous and reversible, since the effects end the moment the lights are shut off. Humans "conquered" the night by illuminating it, and our societies are increasingly more dependent on electrical energy. Therefore, a return to a pristine sky is not expected to occur in many lightpolluted regions. However, there are solutions to diminish the quantity of LP in the environment, such as full shielding the luminaries, limiting the area of lighting, reducing the luminous flux to achieve lower levels of illuminance, shutting off lights when not in use, and limiting growth of installed lighting (Falchi et al., 2011). The major challenge to limiting the impacts of ALAN might in fact be the "trade-off between economic costs and perceived social costs associated with 
implementing these different strategies to managing ALAN" (Gaston et al. 2014).

\section{Dark skies reserves as a safeguard of the night sky}

The creation of dark-skies protected areas is one mechanism to preserve the night sky of some regions, keeping its good dark skies from deteriorating. It is also a way to draw the attention of the public and stakeholders to this growing problem. More than a local effect of large urban centers, LP propagates in the form of skyglow contaminating regions that are tens of kilometers away from those populated regions, affecting locations that originally possessed a good night sky quality just a couple of years ago.

The first International Dark Sky Park was the Natural Bridges National Monument Dark Sky Park (Utah), established in 2007 by the International DarkSky Association (IDA). Today, there are approximately 30 such preserves classified by the IDA as parks or reserves depending on their characteristics (the specifics are beyond the scope of this study but can be obtained at the IDA website, http://www. darksky.org/international-dark-sky-places/about-idsplaces). Other reserves classified by different entities are also being established worldwide revealing growing interest in this subject.

Two regions in Portugal that still have good dark skies are the Peneda-Gerês National Park (PNPG) and Alqueva, located in the north and south of the country, respectively. The sky brightness at these locations has not been measured thus far. However, it is noteworthy that generally the public, amateur astronomers, and tourism promoters have recognized these locales as dark skies sites, suitable for astronomical observations and stargazing. The localization of the areas of study and surrounding regions over a nighttime composite satellite image (VIIRS DNB Cloud Free Composite) is shown in Figure 2.

\section{Materials and methods}

\section{Regions of study}

\section{Alqueva}

The region of the Alqueva Dark Sky Reserve, shown in Figure 3, has a large area of approximately $3000 \mathrm{~km}^{2}$ and a low population density. The mean population density of Portugal is 114.3 inhabitants $/ \mathrm{km}^{2}$ (inh. $/ \mathrm{km}^{2}$ hereafter), whereas in Alqueva it is in the range 5-50 inh. $/ \mathrm{km}^{2}$ (Instituto Nacional de Estatística [INE], 2012), which is one of the lowest densities in

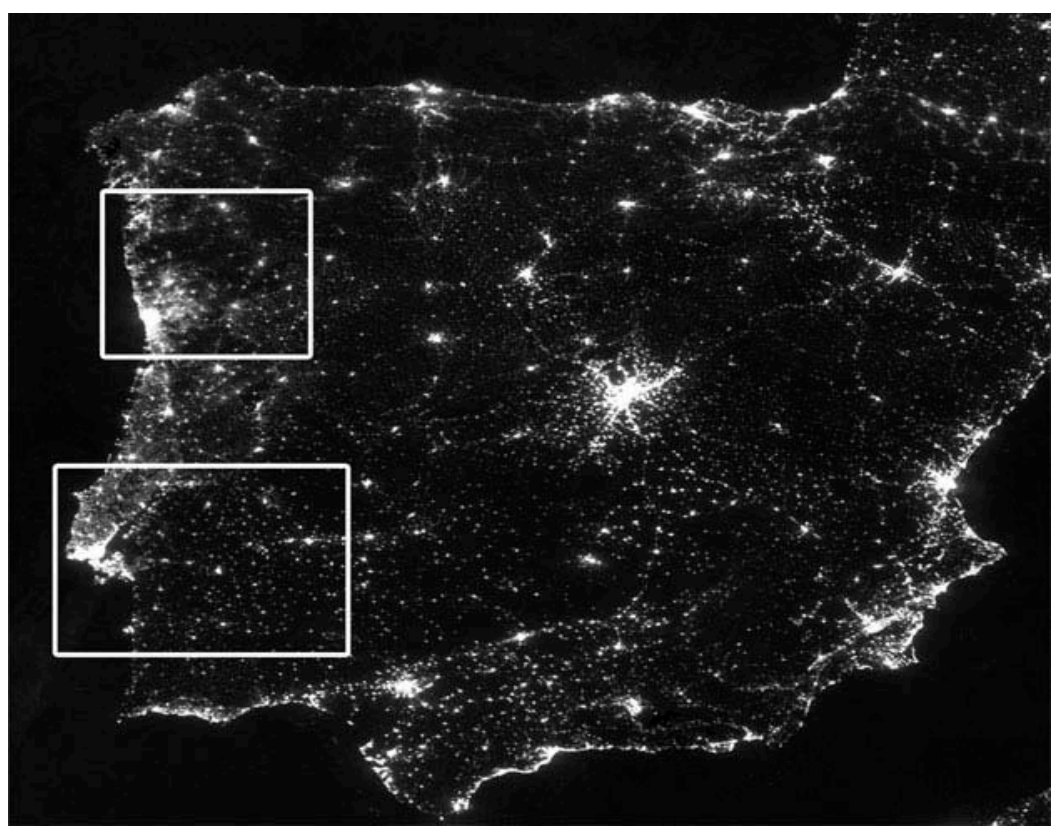

Figure 2. Localization of the areas of study within Portugal and the Iberian Peninsula. The smaller box encompasses the PNPG and all North of Portugal. The brightest patch represents the region known as Grande (Greater) Porto. The larger box encompasses both the Alqueva region and, at the left, the region known as Grande (Greater) Lisboa. The large white patch in the centre of the satellite photograph is Madrid, Spain. (Adapted from: Earth Observation Group, NOAA National Geophysical Data Center. VIIRS DNB Cloud Free Composites). 


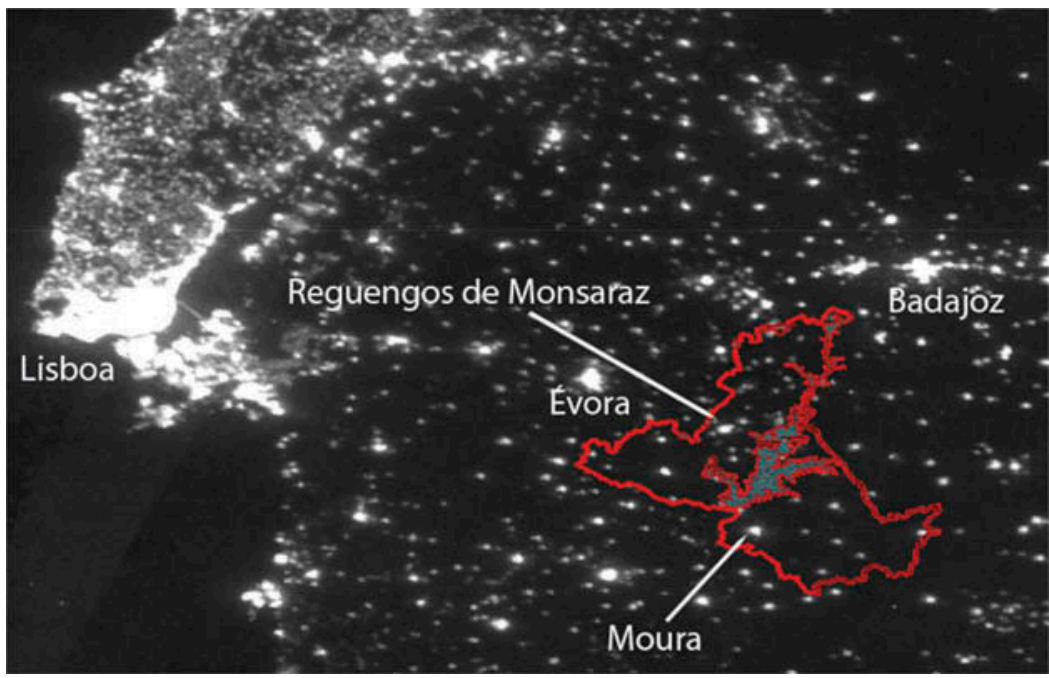

Figure 3. The Dark Sky ${ }^{\circledast}$ Alqueva Reserve and its localization in the south of the country. The right border of the Reserve coincides with the political frontier of Portugal with Spain. Greater Lisboa is represented as Lisboa for the sake of commodity. The grey patch in the middle of the Reserve represents the artificial lake known as Great Lake Alqueva. (Adapted from: Earth Observation Group, NOAA National Geophysical Data Center. VIIRS DNB Cloud Free Composites).

Portugal. The residents are concentrated mainly in small towns and hamlets or in isolated and familiar farms (the "Montes"). The closest city to the reserve is Évora, with approximately 50,000 inhabitants (INE, 2012), at a distance of $30 \mathrm{~km}$ from the west boundary of the Dark Sky Reserve. For comparison, the largest city in the country is Lisbon, $135 \mathrm{~km}$ away from the Reserve, with an estimated population of $547,773 .{ }^{1}$ It is mainly a low-altitude plain region. The climate is of the type-Csa (Koppen), "temperate (mesothermal) with rainy winters, and dry (Mediterranean) and hot summers" (Miranda et al., 1995, p. 10), resulting in a high number of clear nights. Based on a series of studies that began in 2009, including the measurements of sky brightness by Lima (2015), the site has been certified as a "Starlight Tourism Destination," the first site in the world to achieve this certification (December 2011), attributed to the UNTWO and the Starlight Foundation (Starlight, 2011).

\section{The peneda-gerês national park (PNPG)}

Although there are 13 natural parks in Portugal, the Peneda-Gerês Park (PNPG) is the only national park in the country. The distance from the top to the bottom of the park (contour shown in Figure 4) is approximately $45 \mathrm{~km}$. The PNPG has an average population density of 11.15 inh./ $\mathrm{km}^{2}$, ranging between $2.36 \mathrm{inh} . / \mathrm{km}^{2}$ and 63.93 inh. $/ \mathrm{km}^{2}$, with median $9.77 \mathrm{inh} . / \mathrm{km}^{2}$, computed from INE data (INE, 2012), and an estimated population of less than 10,000 today (9071 inhabitants in 2011; INE, 2012) distributed mainly in small villages and hamlets spreading over an area of approximately $710 \mathrm{~km}^{2}$. This distribution is not uniform since there are large uninhabited areas. The park contains a smaller natural reserve: the Baixa Límia-Serra do Xurés Natural Park, Galicia (Spain), which has approximately $293 \mathrm{~km}^{2}$. Both constitute therefore a large area under environmental protection inside a wider region (approximately $2680 \mathrm{~km}^{2}$ ) classified by UNESCO as the Gerês/Xurés Transboundary Biosphere Reserve (Portugal/Spain) (UNESCO, 2009). Contrary to Alqueva, the PNPG is a mountainous territory with its highest peak (Nevosa) reaching an altitude of $1546 \mathrm{~m}$. The climate is also Mediterranean, although more influenced by the Atlantic than in Alqueva. Some regions of the park have the highest rainfall rates of the country, with a mean annual precipitation above $2800 \mathrm{~mm}$ (Santos et al., 2010). The PAN Parks Foundation named the park a Wilderness area in 2008 (Insituto da Conservação da Natureza e das Florestas [ICNF], 2014), mainly for its deep interior areas that are

${ }^{1}$ However, the surrounding area known as Grande Lisboa (Greater Lisbon) has an estimated population of 2,031,170, as of 2013 (PORDATA, 2014). 


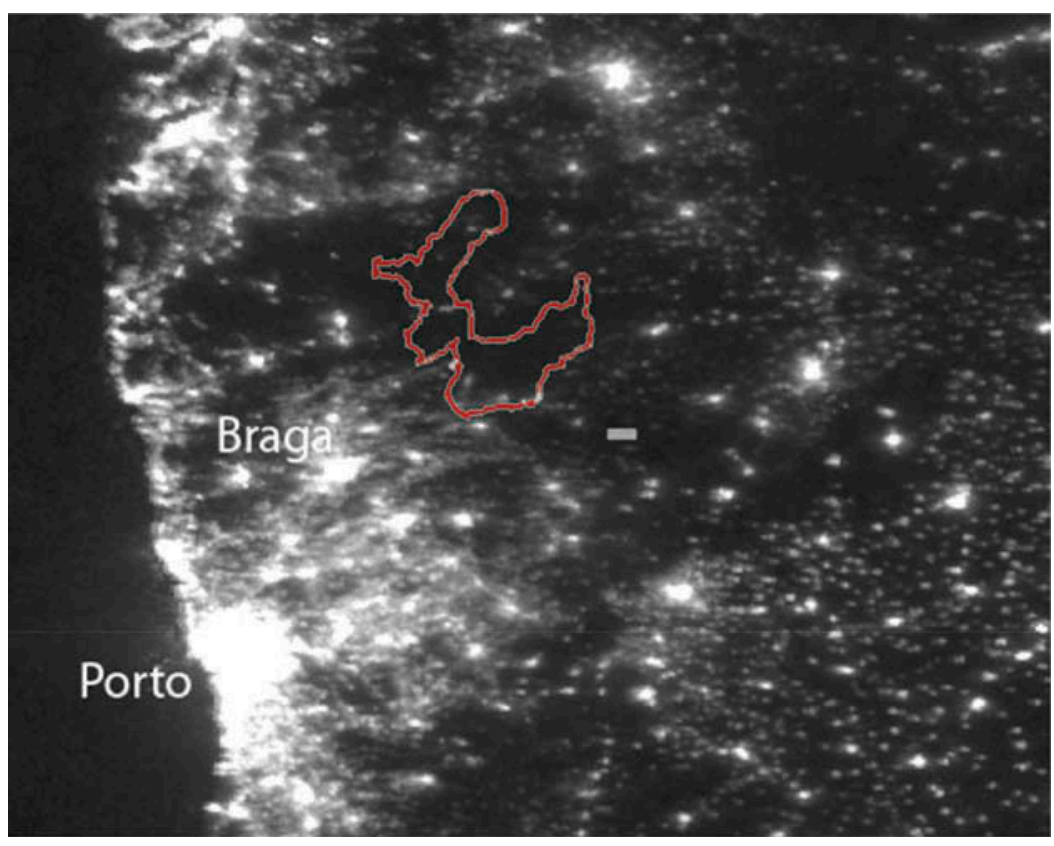

Figure 4. The Peneda-Gerês National Park (PNPG) frontier and its localization in the north of the country. The left border of the " $\mathrm{C}^{\text {" }}$ of the Park also marks part of the political frontier with Galicia, Spain. Greater Porto is represented as Porto for the sake of commodity. The brightest patch SW of the Park is Braga, the largest city nearby. (Adapted from: Earth Observation Group, NOAA National Geophysical Data Center. VIIRS DNB Cloud Free Composites).

unoccupied. Therefore, LP sources are minimal within the park's most interior regions, with the borders being where the major sources of LP are present. As noted from the satellite image shown in Figure 4, the south and the southwest areas are clearly more affected by light originating from the large LP regions outside the park.

\section{Equipment}

For the purpose of measuring how dark the sky of the aforementioned regions might get under clear conditions, measurements were taken at the zenith on moonless nights between the end of astronomical twilights at dusk and beginning of astronomical twilights at dawn (astronomical night) to minimize natural light contribution and guarantee that only ALAN contribution was being measured against natural dark sky brightness. A portable Unihedron Sky Quality Meter-L (serial number: 3840, firmware version 2.17) and an Apple iPhone unit with a global positioning system (GPS) application (Fullpower Technologies MotionX-GPS v21.1) were used for georeferentiation, mostly along the roads that cross both regions. The atmospheric conditions on each measurement were annotated. An outdoor thermometer indicated the approximate local temperatures. The temperature readings provided by the SQM-L unit were not used since the time spent on each data collection was not sufficient for the SQM-L, which was inside the car between stops, to accurately measure the outdoor temperature. The campaigns started in 2010 and the last campaign ended on the summer of 2014. Local humidity data was requested from the Portuguese Institute for the Atmosphere and the Sea (IPMA) for all the campaign dates.

\section{Selection of the time and dates of the observations}

The measurements were all made during astronomical night. The dates were chosen in the calendar between the last quarter and first quarter moon phases, thus maximizing the number of moonless hours per night. Some campaigns were aborted due to weather conditions, either after checking the weather predictions from National Meteorological Institute (Instituto Português do Mar e da Atmosfera, IPMA) or due to the presence 
of fog. Those circumstances caused sometimes the postponing of measurements for 1 or more months, particularly during the colder seasons.

\section{Selection of the observation spots}

To reduce fluctuations in measuring conditions between consecutive data collections, the observations were taken at stops along the roads at 174 points (Alqueva) and 45 points (PNPG) that were selected based upon the following criteria: (i) visual inspection of the night sky and the vicinity; (ii) located $1.5 \mathrm{~km}$ to $3 \mathrm{~km}$ apart, although the distance was dependent on having a safe roadside place; (iii) sky dome near the zenith not covered by any obstacles; and (iv) absence of disturbing streetlights in the area, to avoid stray light entering the sensor.

\section{Visual inspection of the night sky and of the vicinity}

A trained observer is able to judge qualitatively and, to some extent, quantitatively (Globe At Night, 2006) a night sky, by looking at the constellations or the aspect of the Milky Way. However, this judgement is not fully reliable. Even admitting that the eyes of an observer are calibrated from night to night, it is well known that exposure to street lamps or to any other headlights interferes with sensitivity of the eyes after such an exposure. Hence, the presence of panel lights and illumination from the front lights of the car confer an adaptation of the eyes. Some stops were selected in places where there were sudden apparent differences in the sky quality from the previous stop, for example, due to a light dome over a nearby village.

\section{Distance between measurements}

Since there are few artificial light sources at both sites (PNPG and Alqueva), the sky brightness changes slowly along short distances except in the proximity of illuminated places (villages, crossroads), where light intensity varies rapidly and consequently so does the brightness of the sky. Therefore, distances between measurements were chosen in a way such that the values could be considered as representative of the vicinity. A measurement was taken whenever a difference was suspected, regardless of the distance from the previous location, provided the other conditions here listed were met.

\section{Sky dome uncovered}

Points having treetops, power lines, and, more generally, places where a completely clear zone around the zenith was not available were avoided, eventually selecting a location just a few dozen meters away. Treetops covering the roads are frequent in PNPG, but a rare condition in Alqueva.

\section{Absence of streetlights in sight}

The SQM-L has a full width half maximum (FWHM, i.e., the viewing angle at half of its maximal sensitivity) of approximately $20^{\circ}$ (manufacturer data). Nevertheless, to prevent glare and internal reflection, streetlights were avoided whenever possible. In a few exceptions where streetlights were unavoidable, the SQM-L was covered laterally with a dark cloth blocking stray light that could be caught by the lens. Only data obtained under controlled conditions were considered in the analysis. Data from places where light from streetlights could not be fully avoided was rejected.

\section{Limitations}

There were some limitations concerning the places to visit in the territories. The territory of Alqueva is constituted by large private properties. Therefore, except for a few exceptions where permission was granted to measure inside the properties, this study was limited to measuring the skyglow along the roads. Those estates are mainly fields with no lights except for a few exterior lamps at sparse family houses. There is consequently an insignificant contribution to skyglow even if glare might be relevant close to a house. In PNPG, although permission to visit all spots with no limitations was granted from the park, it was only possible to measure along the main roads given that our vehicle was not an all-terrain vehicle and due to difficulty of walking at night through the mountains. 


\section{Using the SQM-L}

Each data point is in fact the average of an array of 12 consecutive readings of the SQM-L pointing to the zenith. Between partial readings the device was rotated around its vertical axis, thus completing a full turn, in order to account for any anisotropy of the SQM-L. Further, the first measurement taken at each spot was rejected, according to the recommendations of the manufacturer, given that the first measurement is generally higher than subsequent values.

\section{Analysis}

The results were treated statistically and plotted using the MATLAB built-in functions meshz.m, TriScatteredInterp.m, and countour.m. For sky brightness, magnitudes per squared arc second $\left(\mathrm{mag} / \operatorname{arcsec}^{2}\right)$, were used as provided by the SQM-L and as a luminance unit commonly used by several investigators (Kyba et al., 2013; Luginbuhl et al., 2014; Bará et al., 2014; Aubé et al., 2014). The conversion to naked eye limiting $\mathrm{V}$ magnitude (NELM) is (Unihedron, 2006)

$$
I[\mathrm{NELM}]=7.93-5 \log \left(10^{4.316-I^{\prime} / 5}+1\right)
$$

with $I^{\prime}$ in $\mathrm{mag} / \operatorname{arcsec}^{2}$.

The results were also compared to the 9-level Bortle (2001) scale, where class 1 is the best achievable on Earth's surface and class 9 corresponds to a strongly light-polluted site. Class 3 is equivalent to a NELM of 6.6 to 7.0 (rural sky); class 4 is equivalent to a NELM of 6.1 to 6.5 (rural/ suburban transition); and class 5 is equivalent to a NELM of 5.6 to 6.0 (suburban sky). Class 9 is equivalent to a NELM of 4 (inner-city sky). The guidelines of the International Dark-Sky Association (IDA) were used to compare the values obtained to the IDA Dark Sky Parks' classification (IDA, 2013, p. 6) (Table 1).

\section{Results}

The data sets were measured mostly in the period from 2009 to 2014, for Alqueva and PNPG. The complete data set (list of coordinates, dates, and SQM readings) is available upon request. For the sake of comparison, some measurements of the sky brightness in two locations inside the city of Porto (northern Portugal) were conducted on various occasions during the same period (20092014), giving values ranging from $17.63 \mathrm{mag} /$ $\operatorname{arcsec}^{2}$ (NELM of 3.65, indicating that only the stars brighter than 3.65 are visible at the zenith) to $18.01 \mathrm{mag} / \operatorname{arcsec}^{2}$ (NELM of 3.97), corresponding to class 9 on the Bortle scale. The normal NELM in clear and unpolluted skies varies from 6 to 7 , approximately, depending on the observer.

\section{Alqueva}

In this study the sky brightness at 174 locations was determined at some of sites more than once in different years and seasons. Some places had an excellent sky quality reaching a maximum of 21.88 $\mathrm{mag} / \operatorname{arcsec}^{2}$ at one of the locations. Averaging the readings obtained in the different seasons and years, the territory of the Reserve Dark Sky Alqueva had a mean value of $21.43 \mathrm{mag} / \mathrm{arcsec}^{2}$ and a median also of $21.43 \mathrm{mag} / \mathrm{arcsec}^{2}$ with a standard deviation of $0.24 \mathrm{mag} / \mathrm{arcsec}^{2}$.

Only two regions were found to have values below $21 \mathrm{mag} / \operatorname{arcsec}^{2}$ equivalent to a sky with a NELM of 6.1. One of those regions falls within the range of distances of 1.2 to $4 \mathrm{~km}$ from the center of Reguengos de Monsaraz-set to avoid streetlights. The other was at an open car park in Monsaraz, chosen for comparison with the vicinity, where a value of $20.6 \mathrm{mag} / \mathrm{arcsec}^{2}$ was found. Actions to reduce the light pollution in Monsaraz were taken following our campaign. A measuring campaign in the near future to assess the improvements is being planned.

Of the 174 different places examined, 21 (11.8\%) showed sky brightness above or equal to

Table 1. Dark Sky Park tier designation

\begin{tabular}{lccc}
\hline Dark Sky Park tier designation & Gold & Silver & Bronze \\
\hline Unihedron Sky Quality Meter $\left(\mathrm{mag} / \mathrm{arcsec}^{2}\right)$ & $\geq 21.75$ & {$[21.75-21.00]$} & {$[21.00-20.00]$} \\
\hline
\end{tabular}

Note. The International Dark-Sky Association Dark Sky Parks' classification. All values are in mag/arcsec ${ }^{2}$. 
Table 2. Summary of results for Alqueva and PNPG.

\begin{tabular}{lcr}
\hline & Alqueva & PNPG \\
\hline Minimum & 20.44 & 20.95 \\
Maximum & 21.88 & 21.58 \\
Median & 21.43 & 21.25 \\
Mean & 21.43 & 21.29 \\
Std. deviation & 0.24 & 0.19 \\
\hline
\end{tabular}

Note. For Alqueva 174 data points and for PNPG 50 data points. All values are in mag/arcsec ${ }^{2}$.

$21.75 \mathrm{mag} / \operatorname{arcsec}^{2}$ (classes 3 and 4 on the Bortle scale) and $150(84.3 \%)$ of them displayed sky brightness between $21 \mathrm{mag} / \operatorname{arcsec}^{2}$ and 21.75 mag/arcsec ${ }^{2}$ (class 4 on the Bortle scale). Consequently, although only places far from streetlamps and without interfering glare were determined, only 7 (3.9\%) of the places measured within Alqueva demonstrated a sky brightness between $20 \mathrm{mag} / \operatorname{arcsec}^{2}$ and $20.99 \mathrm{mag} / \operatorname{arcsec}^{2}$ (classes 4 and 5 on the Bortle scale) (Table 2). Some of the results are shown in Figure 5.

\section{Peneda-Gerês national park}

Of all the 50 measurements for the spots selected in PNPG, 47 fell in the range $21 \mathrm{mag} / \operatorname{arcec}^{2}$ to $21.75 \mathrm{mag} / \mathrm{arcsec}^{2}$, with a mean of $21.29 \mathrm{mag} /$ $\operatorname{arcsec}^{2}$ and a median of $21.25 \mathrm{mag} / \operatorname{arcsec}^{2}$, corresponding to a NELM of approximately 6.3 (Table 2). Only 3 measurements fell in the range $20 \mathrm{mag} / \operatorname{arcsec}^{2}$ to $20.99 \mathrm{mag} / \mathrm{arcsec}^{2}$, but the sky had a few clouds on those three determinations, thus having an expected higher brightness. The standard deviation is $0.19 \mathrm{mag} / \operatorname{arcsec}^{2}$. The worst measurement was $20.95 \mathrm{mag} / \mathrm{arcsec}^{2}$ (NELM of 6.1) and the best was $21.58 \mathrm{mag} / \operatorname{arcsec}^{2}$ (NELM of 6.4). The inner parts of the park (not measured) are expected to display a higher NELM since there are no local sources of LP. The results for Alqueva and PNPG are summarized in Table 2.

\section{Discussion}

Concerning the brightness of the night sky, the results showed that both the regions of Alqueva and PNPG may be considered at least on a par with other global protected regional dark skies. Examples of International Dark Sky Reserves with similar values for the night sky brightness include Brecon Beacons National Park (Wales, UK), Rhön International Dark Sky Reserve/ Sternenpark Rhön Hesse (Bavaria and Thuringia, Germany), and the Exmoor National Park (United Kingdom), to name just three in Europe that are designated on an equal tier by the International Dark-Sky Association (IDA, 2014). Global sky glow is gradually increasing due to human-made lighting of the night sky. Both Alqueva and PNPG

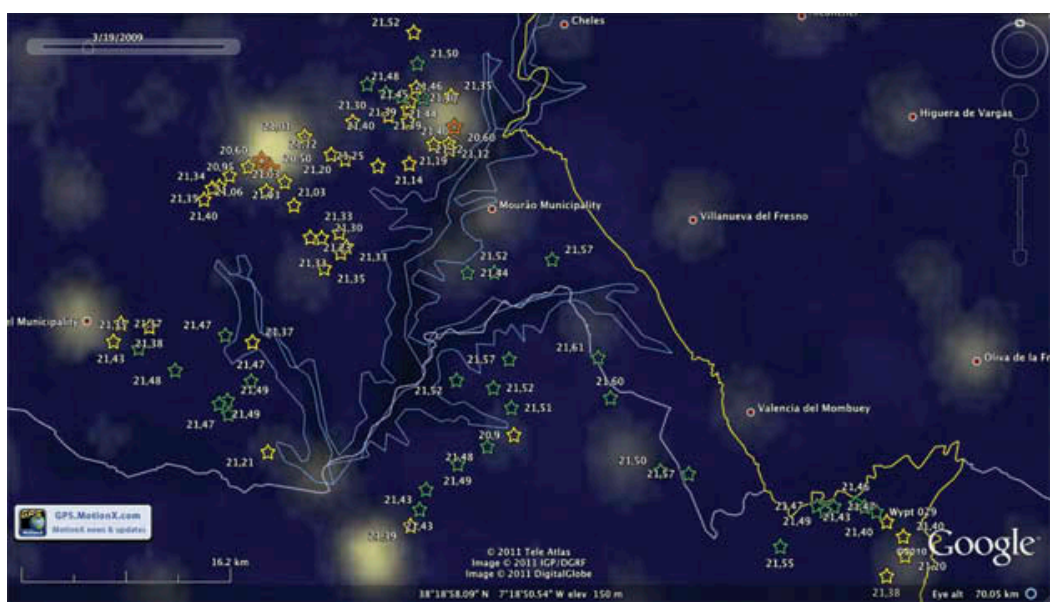

Figure 5. Sample of results for Alqueva from one of the campaigns superimposed to the NASA Earth City Lights layer of Google Earth. The brightest patch at upper left is Reguengos de Monsaraz. The bright patch at bottom left is from the city of Moura. All values are in mag/arcsec ${ }^{2}$. 
still offer the bright-dark middle latitudes natural cycle, which is gradually disappearing, attributed to more populated regions in Portugal.

The Dark Sky Alqueva Reserve has a large area of almost continuous good-quality night sky darkness, negatively affected only at regions close to its main populated areas, including Reguengos de Monsaraz (population 7261 inhabitants; INE, 2012) (Figure 3). There is an increase in the skyglow in the vicinity of the small towns within the reserve. A few hundred meters away from those towns, the sky quality improves swiftly. The main contribution to the nonnatural skyglow, although generally weak, arises from more urbanized locations near the border of the reserve (namely, Reguengos de Monsaraz) and also from more densely populated regions at distances of tens of kilometers from the reserve limits.

The results for the smaller and loosely populated PNPG demonstrated that it is mostly affected by LP from outside the park at its south and southwestern-most areas, as would be expected from inspection of satellite imagery. At the south, many highly concentrated populated areas prevail (regions known as Comunidades Intermunicipais of Alto Minho, Cávado, Alto Tâmega, Ave and Grande Porto). Therefore, LP contributing to the skyglow here originated predominantly from those sources at distances ranging from the vicinity of the park to tens of kilometres, depicted in Figure 6.

In both regions, public lighting comes from low-pressure sodium vapor (LPS), high-pressure sodium vapor (HPS), $\mathrm{Hg}$, and metal halide lamps and LED. Although the percentages of streetlights by type are currently unknown, a primer inspection in the terrain revealed predominance in both LPS and HPS lamps. The orange halo from those higher wavelengths lights above the populated places is therefore prevalent.

In both Alqueva and PNPG the contribution from small towns to the skyglow is almost negligible except from within those towns and in its close vicinity, where glare from bad lighting blocks the vision of all but the brightest stars. A few hundred meters away from those places the sky darkness is again of good quality, as the sky brightness diminishes sharply. The LP regulation of the PNPG management plan is important, but the park would benefit from a major plan of LP control in the surrounding urban areas. The LP regulation included in the management plan of the Alqueva Dark Sky Reserve seems sufficient if respected, but the region may benefit if better lighting is used. A reduction of LP from distant regions would represent a global improvement in the skyglow in both regions.

The night skies in both Alqueva and PenedaGerês, albeit regions with different characteristics, possess good quality that needs to be preserved. With LP recognized as a growing menace to the environment and a possible risk factor to human health, there is emphasis on the necessity of continuous monitoring of LP to minimize its impacts, especially in populated areas both to reduce the exposed population to ALAN and avoid propagation of ALAN to well-preserved locations.

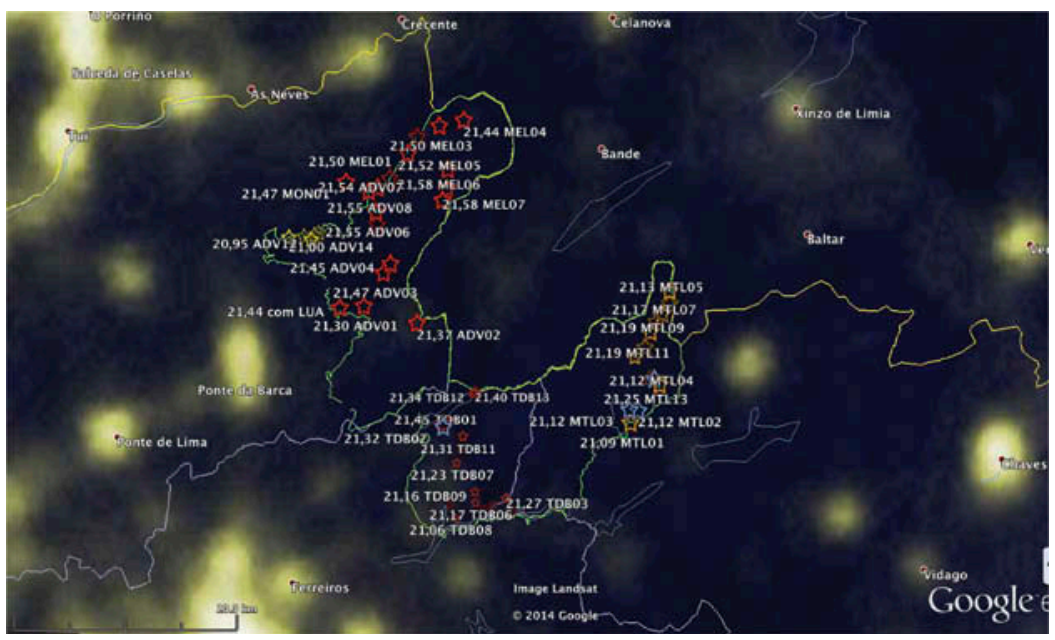

Figure 6. The 50 results for the Peneda-Gerês National Park (green contour) superimposed to the NASA Earth City Lights layer of Google Earth. All values are in mag/arcsec ${ }^{2}$. 
Parts of these results were instrumental for classification of Alqueva as a "Starlight Tourism Destination" by the Starlight Foundation (UNESCO/United Nations World Tourism Organization/Instituto de Astrofisica de Canarias). The Dark Sky Alqueva Reserve was the first site in the world to achieve such a certification (December 2011). The first results for PNPG from this investigation were also used for regulations concerning LP within the park, which became effective as part of the park's last management plan (DR 2011, 682-(16)).

Preservation depends on several participants, from energy suppliers to stakeholders and all citizens, to whom it needs to be stressed that LP control is beneficial to society. Professional astronomy is also a priority in many countries, representing sometimes a large financial effort. Consequently, it is of importance to uphold existing dark skies reserves and promote establishment of new ones. Since excessive ALAN is recognized as a form of pollution with effects on health and environment, the key role that health environmentalists may have as researchers and as interveners on outdoor light control and regulation is thus stressed.

\section{Conclusions}

The sky brightness of two regions in Portugal, the Alqueva and the PNPG Park, known to have good quality regarding darkness was measured and analyzed, in order to assess the major sources of LP affecting those areas. To our knowledge, these are the first determinations of the night sky brightness obtained from the ground in these regions. The results from the study of both regions revealed dark skies comparable to other dark sky protected areas worldwide. There is increasingly more evidence of possible negative effects of ALAN on health and on the environment. The monitoring and maintenance of Alqueva and the PNPG as dark skies sites are therefore critical for current and future interdisciplinary research including effects on health and on the environment.

\section{Funding}

NP acknowledges funding by the Gemini-Conicyt Fund, allocated to project number 32120036, and by the Portuguese FCT - Foundation for Science and Technology and the European Social Fund (ref: SFRH/BGCT/113686/ 2015). RL acknowledges support from the Programa de Formação Avançada de Docentes by the IPP (Instituto Politécnico do Porto). RL thanks Dr. Constance Walker (NOAO), for kindly providing the SQM-L used for this work, Dr. Ana Fontes and Eng. Lagido Domingos (PNPG), and Dr. Pedro Oliveira (ICBAS, University of Porto). CITEUC is funded by National Funds through FCT Foundation for Science and Technology (project: UID/ Multi/00611/2013) and FEDER - European Regional Development Fund through COMPETE 2020 - Operational Programme Competitiveness and Internationalisation (project: POCI-01-0145-FEDER-006922).

\section{Orcid}

Raul Cerveira Lima (D) http://orcid.org/0000-0001-7212-510X José Pinto da Cunha (D http://orcid.org/0000-0002-9049-0693 Nuno Peixinho (D) http://orcid.org/0000-0002-6830-476X

\section{References}

American Medical Association. 2012. Council on Science and Public Health Report 4. Light pollution: Adverse health effects of nighttime lighting. June. Chicago, IL: American Medical Association House of Delegates Annual Meeting.

Aubé, M., Fortin, N., Turcotte, S., García, B., Mancilla, A., and Maya, J. 2014. Evaluation of the sky brightness at two Argentinian astronomical sites. Publ. Astron. Soc. Pac. 126: 1068-1077.

Bará, S. 2014. Galician Night Sky Brightness Monitoring Network. http://webspersoais.usc.es/persoais/salva.bara/ GalicianNSBnetwork.html (Accessed December 2, 2014).

Bará, S., Nievas, M., Sánchez de Miguel, A., and Zamorano, J. 2014. Zernike analysis of all-sky night brightness maps. Appl. Opt. 53: 2677-2686.

Bortle, J.- E. 2001. Light pollution and astronomy: The Bortle Dark Sky Scale. Sky \& Telescope, February. http://www. skyandtelescope.com/astronomy-resources/light-pollutionand-astronomy-the-bortle-dark-sky-scale

Bullough, J. D., Rea, M. S., and Figueiro, M. G. 2006. Of mice and women: Light as a circadian stimulus in breast cancer research. Cancer Causes Control 17: 375-383.

Chellappa, S. L., Steiner, R., Oelhafen, P., Lang, D., Götz, T., Krebs, J., and Cajochen, C. 2013. Acute exposure to evening blue-enriched light impacts on human sleep. J. Sleep Res. 22: 573-580.

Cinzano, P., Falchi, F., and Elvidge, C. D. 2001. The first World Atlas of the artificial night sky brightness. Monthly Not. R. Astron. Soc. 328: 689-707.

Cohen, A. J., H., Anderson, H. R., Ostro, B., Pandey, K. D., Krzyzanowski, M., Künzli, N., Gutschmidt, K., Pope, A., Romieu, I., Samet, J. M., and Smith, K. 2005. The global burden of disease due to outdoor air pollution. J. Toxicol. Environ. Health A 68: 1301-1307.

Costa, D. L. 2004. Issues that must be addressed for risk assessment of mixed exposures: The U.S. EPA 
experience with air quality. J. Toxicol. Environ. Health A 67: 195-207.

Costa, S., Ferreira, J., Silveira, C., Costa, C., Lopes, D., Relvas, H., Borrego, C., Roebeling, P., Miranda, A. I., and Teixeira, J. P.2014. Integrating health on air quality assessment -Review report on health risks of two major European outdoor air pollutants: $\mathrm{PM}$ and $\mathrm{NO}_{2}$. J. Toxicol. Environ. Health B 17: 307-340.

DR. 2011. Resolução do Conselho de Ministros n. ${ }^{\circ}$ 11-A/ 2011. Diário da República 1. ${ }^{a}$ séRie 25: 682(2)- 682(30).

Falchi, F., Cinzano, P., Elvidge, C. D., Keith, D. M., and Haim, A. 2011. Limiting the impact of light pollution on human health, environment and stellar visibility. J. Environ. Manage. 92: 2714-2722.

Filipski, E., Li, X. M., and Lévi. F. 2006. Disruption of circadian coordination and malignant growth. Cancer Causes Control 17: 509-514.

Gaston, K. J., Bennie, J., Davies, T. W., and Hopkins, J. 2013. The ecological impacts of nighttime light pollution: A mechanistic appraisal. Biol. Rev. 88: 912-927.

Gaston, K. J., Duffy, J. P., Gaston, S., Bennie, J., and Davies, T. W. 2014. Human alteration of natural light cycles: Causes and ecological consequences. Oecologia 176: 917-931.

Globe At Night. 2006. Magnitude charts for the constellation Perseus at $40 \mathrm{~N}$. http://www.globeatnight.org/magcharts (accessed November 20, 2014).

Gathreaux, S. A., Jr., and Belser, C. G. 2006. Effects of artificial night lighting on migrating birds. In Ecological consequences of artificial night lighting, ed. C. Rich and T. Longcore, 67-93. Washington, DC: Island Press.

Haim, A., and Portnov, B. A. 2013. Light pollution as a new risk factor for human breast and prostate cancers. Dordrecht, The Netherlands: Springer.

Insituto da Conservação da Natureza e das Florestas. 2014. Rede Pan Parks. Instituto da Conservação da Natureza e Florestas. http://www.icnf.pt/portal/turnatur/pan-parks (accessed December 1, 2014).

Instituto Nacional de Estatística. 2012. Censos 2011 Anuário Estatístico de Portugal Edição 2012-Statistical Yearbook of Portugal. Lisboa, Portugal: Instituto Nacional de Estatística.

International Agency for Research on Cancer. 2010. Painting, firefighting, and shiftwork. IARC monogr. Eval. Carcinogen. Risks hum, 98. Lyon, France: World Health Organization.

International Dark-Sky Association. 2013. International Dark-Sky Association Dark Sky Park program criteria, May 2013. International Dark-Sky Association. http:// www.darksky.org/idsp/Guidelines/IDSP\%20Guildelines\% 20Final-May13-BP.pdf.

International Dark-Sky Association. 2014. International Dark Sky Places. http://darksky.org/international-dark-skyplaces/about-ids-places (accessed November 28, 2014).

Jasser, S. A., Blask, D. E., and Brainard, G. C. 2006. Light during darkness and cancer: Relationships in circadian photoreception and tumor biology. Cancer Causes Control 17: 515-523.
Krzyzanowski, M. 2008. WHO air quality guidelines for Europe. J. Toxicol. Environ. Health A 71: 47-50.

Kyba, C. C. M., Wagner, J. M., Kuechly, H. U., Walker, C. E., Elvidge, C. D., Falchi, F., Ruhtz, T., and Hölker, F. 2013. Citizen science provides valuable data for monitoring global night sky luminance. Sci. Rep. 3: 1835.

Liang, G., Schernhammer, E., Qi, L., Gao, X., De Vivo, I., and Han, J. 2011. Associations between rotating night shifts, sleep duration, and telomere length in women. PLoS ONE 6: e23462.

Lima, R. 2015. Light pollution: measuring and modelling skyglow. An application in two Portuguese reserves. Doctoral thesis. Coimbra. http://hdl.handle.net/10316/28773

Longcore, T., and Rich, C. 2006. Synthesis. In Ecological consequences of artificial night lighting, ed. C. Rich and T. Longcore, 413-430. Washington, DC: Island Press.

Luginbuhl, C. B., Boley, P. A., and Davis, D. R. 2014. The impact of light source spectral power distribution on sky glow. J. Quant. Spectrosc. Radiat. Transfer 139: 21-26.

Luginbuhl, C. B., Walker, C. E. and Wainscoat, R. 2009. Lighting and astronomy. Phys. Today 62: 32-37.

Miranda, P. M. A., Abreu, F. and Salgado, R. 1995. Estudo de Impacte Ambiental do Alqueva-Clima: Relatório final. Final report from the Instituto de Ciência Aplicada e Tecnologia, Lisboa, Portugal: Universidade de Lisboa. http://194.117.7.100/Download/alqueva\%20completo.pdf.

Navara, K. J., and Nelson, R. J. 2007. The dark side of light at night: Physiological, epidemiological, and ecological consequences. J. Pineal Res. 43: 215-224.

PORDATA. 2014."PORDATA: Resident population in municipalities. http://www.pordata.pt/en/Municipalities/ Resident+population-359.

Proietti, S., Cucina, A., Reiter, R. J., and Bizzarri, M. 2013. Molecular mechanisms of melatonin's inhibitory actions on breast cancers. Cell. Mol. Life Sci. 70: 2139-2157.

Santos, C. D., Miranda, A. C., Granadeiro, J. P., Lourenço, P. M., Saraiva, S., and Palmeirim, J. M. 2010. Effects of artificial illumination on the nocturnal foraging of waders. Acta Oecol. 36: 166-172

Santos, J. F., Pulido-Calvo, I., and Portela, M. M. 2010. Spatial and temporal variability of droughts in Portugal. Water Resource Res. 46: 1-13.

Schernhammer, E. S., Laden, F., Speizer, F. E., Willet, W. C., Hunter, D. J., Kawachi, I., Fuchs, C. S., and Colditz, G. A. 2003. Nightshift work and risk of colorectal cancer in the nurses' health study. J. Natl. Cancer Inst. 95: 825-828.

Starlight. 2007. Declaration in defence of the night sky and the right to starlight (La Palma declaration). In Starlight: A common heritage, ed. C. Marín and J. Jafari, 455-457. La Palma, Spain: Starlight Initiative and Instituto de Astrofísica de Canarias (IAC). http://www.starlight2007. net/pdf/StralightCommonHeritage.pdf.

Starlight. 2011. Alqueva, Portugal-Starlight Tourism Destination. http://www.starlight2007.net/index.php?option= com_content\&view=article\&id=370\%3Aalqueva-the-first-star light-destination\&catid=59\%3Anews-features\&Itemid= 166\&lang=en (accessed December 7, 2014). 
Stevens, R. G. 2006. Artificial lighting in the industrialized world: Circadian disruption and breast cancer. Cancer Causes Control 17: 501-507.

Stevens, R. G., Brainard, G. C., Blask, D. E., Lockley, S. W., and Motta, M. E. 2013. Adverse health effects of nighttime lighting. Comments on American Medical Association Policy Statement. Am. J. Prev. Med. 45: 343-346.

Stone, E. L., Jones, G., and Harris, S. 2012. Conserving energy at a cost to biodiversity? Impacts of LED lighting on bats. Global Change Biol. 18: 2458-2465.

Tan, D., Chen, L., Poeggeler, B., Manchester, L. C., and Reiter, R. J. 1993. Melatonin-A potent, endogenous hydroxyl radical scavenger. Endocr. J. 1: 57-60.

UNESCO. 2009. Ecological sciences for sustainable development: Europe \& North America (290 biosphere reserves in 36 countries). http://www.unesco.org/new/en/natural-sciences/ environment/ecological-sciences/biosphere-reserves/europenorth-america (accessed November 28, 2014).

Unihedron. 2006. Conversion calculator-NELM (V) to MPSAS (B) systems. http://www.unihedron.com/projects/ darksky/NELM2BCalc.html (accessed November 29, 2014).

Waldram, J. M. 1972. The calculation of sky haze luminance from street lighting. Lighting Res. Technol. 4: 21-26.

Walker, M. F. 1977. The effects of urban lighting on the brightness of the night sky. Publ. Astron. Soc. Pac. 89: 405-409.

Wyse, C. A., Selman, C., Page, M. M., Coogan, A. N., and Hazlerigg, D. G. 2011. Circadian desynchrony and metabolic dysfunction: Did light pollution make us fat? Med. Hypoth. 77: 1139-1144. 